\title{
Analyses of physicochemical properties, bacterial microbiota, and lactic acid bacteria of fresh camel milk collected in Inner Mongolia
}

\author{
Jingna Zhao, ${ }^{1,2} \oplus$ Hui Fan, ${ }^{1,2}$ Lai-Yu Kwok, ${ }^{1,2}$ ๑) Fucheng Guo, ${ }^{1,3}$ Rimutu Ji, ${ }^{1,3}$ Mei Ya, ${ }^{4}$ and Yongfu Chen ${ }^{1,2 *}$ (]) \\ ${ }^{1}$ Key Laboratory of Dairy Biotechnology and Engineering, Ministry of Education, Inner Mongolia Agricultural University, Hohhot, \\ Inner Mongolia 010018, China \\ ${ }^{2}$ Key Laboratory of Dairy Products Processing, Ministry of Agriculture and Rural Affairs, Hohhot, Inner Mongolia 010018, China \\ ${ }^{3}$ Inner Mongolian Institute of Camel Research, Hohhot, Inner Mongolia 010018, China \\ ${ }^{4}$ Xilingol Vocational College, Xilinhot, Inner Mongolia 026000, China
}

\section{ABSTRACT}

Camel milk has significant economic value and is an important food in the region of Alxa Left Banner of Inner Mongolia. Fifteen fresh camel milk samples were collected from domesticated camels in a pasture of Alxa Left Banner. The physicochemical properties and bacterial diversity of camel milk samples were analyzed. The average values of fat, total protein, nonfat milk solids, acidity, and density were $4.40 \%, 3.87 \%, 9.50 \%, 16.95^{\circ} \mathrm{T}$, and $1.02 \mathrm{~g} / \mathrm{cm}^{3}$, respectively. The bacterial microbiota of the collected fresh camel milk was investigated using PacBio single-molecule real-time (Pacific Biosciences, Menlo Park, CA) sequencing. The camel milk microbiota was highly diverse and comprised 8,513 operational taxonomic units belonging to 32 phyla, 377 genera, and 652 species. The major phyla included Proteobacteria, Firmicutes, Deinococcus-Thermus, Bacteroidetes, and Actinobacteria. A small number of lactic acid bacteria sequences were detected, representing the species Streptococcus thermophilus, Lactobacillus helveticus, Lactococcus lactis, and Leuconostoc mesenteroides. A total of 72 strains of lactic acid bacteria were isolated and identified from 15 samples, including Lactobacillus paracasei, Enterococcus italicus, Enterococcus durans, Lactococcus lactis ssp. lactis, Weissella confusa, and Enterococcus faecium. These results confirm that fresh camel milk has a high bacterial diversity and is a valuable natural resource for isolation of novel lactic acid bacteria.

Key words: camel milk, bacterial microbiota, lactic acid bacteria, single-molecule real-time sequencing, Alxa Left Banner

Received May 26, 2019.

Accepted August 29, 2019.

*Corresponding author: nmgyfchen@126.com

\section{INTRODUCTION}

Bactrian camels are found in the desert zone of central Asia and China (Kadim et al., 2008). There are approximately 316,000 Bactrian camels in China (China Statistical Yearbook, 2013), mainly domesticated in Inner Mongolia, Xinjiang, Qinghai, Gansu, Ningxia, and other provinces. Alxa Left Banner is a region within Inner Mongolia. As the main livestock in Alxa Left Banner, Bactrian camels are an important economic species for local herdsmen. Camel milk has been part of the daily diet of nomadic people for centuries, and it has good nutritional and medicinal properties (Yagil, 1982; Shabo et al., 2005). Its biochemical composition is close to that of human milk, and it has a relatively low fat content and is rich in vitamins (Zibaee et al., 2015). Moreover, camel milk contains all the essential nutrients needed for human, so it can serve as an alternative to bovine milk (Shamsia, 2007; El-Agamy et al., 2009; Bulca, 2017). One additional advantage is its low allergenicity (Teply, 1965; Zibaee et al., 2015).

Aside from the physicochemical properties and nutritional composition of camel milk, a rich bacterial diversity exists in the milk, particularly in lactic acid bacteria (LAB; Khedid et al., 2009), which can contribute to the functional and desirable qualities of camel milk (Jans et al., 2012). Much effort has been devoted to research the yield of camel milk and its nutritional values (Bai et al., 2009; Zhao et al., 2015), as well as its medicinal values (Kula and Tegegne, 2016). However, the bacterial composition of camel milk has not been studied systematically. Lactic acid bacteria not only contribute to the sensorial and textural properties of dairy products but also help produce bioactive substances, such as bacteriocins and organic acids, that suppress the growth of potential pathogens (Leroy and De Vuyst, 2004). The presence of Lactobacillus, Lactococcus, Streptococcus, and Enterococcus in camel milk has been reported previously (Khedid et al., 2009). 
Other than gaining an understanding of the nutritional value of camel milk, it is important to profile its microbiota with respect to food safety and milk quality assessment (Benkerroum et al., 2003). Similar to other types of milk, camel milk contains a high level of microorganisms, reaching $10^{5} \mathrm{cfu} / \mathrm{mL}$ (Dong et al., 2012). Therefore, studying the intrinsic microbiota composition is of high practical significance for the industrialization and promotion of camel milk. High-throughput sequencing has become a common technique to investigate microbial communities present in food products including milk (Ercolini, 2013; Li et al., 2017; Jin et al., 2018). It overcomes the limitation of isolating fastidious microbes using culture-dependent methods. For example, donkey milk bacterial communities were found to comprise 5 major phyla: Proteobacteria, Firmicutes, Bacteroidetes, Actinobacteria, and Verrucomicrobia (Soto Del Rio et al., 2017). Until now, most available reports studying camel milk microbiota have been based on culture-dependent methods (Benkerroum et al., 2003; Omer and Eltinay, 2008; Yamina et al., 2013; Ayyash et al., 2018). The complete profile of the camel milk microbiota has not yet been described by a high-throughput sequencing approach, although high-throughput sequencing has been used to identify possible sources of raw milk contamination (Heikkilä and Saris, 2003; Hou et al., 2015; Wang et al., 2018).

The application of PacBio single molecule real-time (SMRT; Pacific Biosciences, Menlo Park, CA) sequencing technology can achieve high taxonomic resolution, up to the species level, when combined with full-length 16S rRNA gene sequencing (Mosher et al., 2014). In the current study, we applied this technology to detect the bacterial microbiota of 10 camel milk samples collected in the Alxa Left Banner region. We focused on isolating and identifying LAB from 15 fresh camel milk samples by culture-dependent methods. Data generated from this work provide interesting information about the bacterial community of camel milk, which is valuable to the industry in search of novel functional LAB resources.

\section{MATERIALS AND METHODS}

\section{Sample Collection}

Fifteen fresh camel milk samples were collected on a farm in Alxa Left Banner of Inner Mongolia in March 2018. The teats of the cows were cleaned with $70 \%$ ethanol, and a few streams of foremilk were discarded before sample collection. All samples were stored in 50$\mathrm{mL}$ sterile centrifuge tubes and stored at $4^{\circ} \mathrm{C}$ before being transported to the laboratory in an ice box within $24 \mathrm{~h}$ of collection. Upon arrival at the laboratory, half of each sample was stored frozen at $-80^{\circ} \mathrm{C}$ for DNA extraction and sequencing. The remaining half was used immediately for microbiological and physicochemical analyses.

\section{Physicochemical Analyses of Fresh Camel Milk}

Physicochemical analyses of 10 of the fresh camel milk samples were performed following the methods of the National Food Safety Standards (2010, 2016a,b,c,d) of China. The contents of fat, protein, nonfat milk solids, acidity, and density were measured by the methods described in the guidelines (GB5009.6-2016, GB5009.5-2016, GB5413.39-2010, GB5009.239-2016, and GB5009.2-2016, respectively).

\section{Enumeration and Isolation of $L A B$}

Camel milk LAB counts of all 15 samples were determined by plate count. One milliliter of sample was serially diluted with $9 \mathrm{~mL}$ of sterile physiological saline $(0.85 \% \mathrm{NaCl}, \mathrm{wt} / \mathrm{vol})$ to a dilution of $10^{-3}$. Then, a 1-mL aliquot of each diluted sample was used to determine counts (cfu) by pour plate method with de Man, Rogosa and Sharpe agar (MRS: Oxoid/Shanghai Harmony Biotechnology Co. Ltd., Shanghai, China). Agar plates were incubated at $37^{\circ} \mathrm{C}$ for 36 to $48 \mathrm{~h}$ anaerobically $\left(\mathrm{CO}_{2}: \mathrm{H}_{2}: \mathrm{N}_{2}=10: 10: 80\right)$. After incubation, only plates with 30 to 300 colonies were selected for counting. Data were expressed as colony-forming units per milliliter of milk. All experiments were performed in triplicate.

For isolation of LAB, $200 \mu \mathrm{L}$ of diluted sample from each diluted gradient was spread on MRS or M17 agar (Oxoid/Shanghai Harmony Biotechnology Co. Ltd.). Plates were incubated at $37^{\circ} \mathrm{C}$ for 36 to $48 \mathrm{~h}$ anaerobically. Colonies with distinct morphology resembling that of LAB were selected and purified by streaking. All isolates were gram-positive and catalase-negative. Isolated strains were subcultured in M17 and MRS broths (both from Oxoid) to maintain purity and for subsequent experiments. Frozen stocks were made to preserve isolated strains.

\section{Identification of Selected Isolates by $16 S$ rRNA Sequencing}

Genomic DNA of the purified isolates was extracted using a commercial kit (Tiangen Biotech Co. Ltd., Beijing, China), and the concentration and purity of the genomic DNA were checked with an ND-1000 type micro UV spectrophotometer (Thermo Fisher Scientific, Waltham, MA). The $16 \mathrm{~S}$ rRNA gene was amplified on a thermal cycler (PTC-200, MJ Research, 
Waltham, MA) using genomic DNA as template with the universal bacterial $16 \mathrm{~S}$ rRNA gene primers: $27 \mathrm{~F}$ (5'-GCAGAGTTCTCGGAGTCACGAAGAGTTTGATCCTGGCTCAG-3') and 1495R (5'-AGCGGATCACTTCACACAGGACTACGGCTACCTTGTTACGA-3') (Scarpellini et al., 2002). The 50- $\mu$ L PCR included $5 \mu \mathrm{L}$ of $10 \times$ PCR buffer, $4 \mu \mathrm{L}$ of dNTP $(2.5$ $\mathrm{mmol} / \mathrm{L}), 1.5 \mu \mathrm{L}$ of $27 \mathrm{~F}$ primer $(10 \mathrm{mmol} / \mathrm{L}), 1.5 \mu \mathrm{L}$ of $1495 \mathrm{R}$ primer $(10 \mathrm{mmol} / \mathrm{L}), 1.5 \mu \mathrm{L}$ of DNA template, and $0.5 \mu \mathrm{L}$ of $T a q$ DNA polymerase $(5 \mathrm{U} / \mu \mathrm{L})$. The PCR amplification cycle parameters were as follows: predenaturation at $94^{\circ} \mathrm{C}$ for $5 \mathrm{~min}$; denaturation at $94^{\circ} \mathrm{C}$ for $1 \mathrm{~min}$, annealing at $58^{\circ} \mathrm{C}$ for $1 \mathrm{~min}$, and extension at $72^{\circ} \mathrm{C}$ for $2 \mathrm{~min}$. Cycles were repeated 30 times, followed by an extension step at $72^{\circ} \mathrm{C}$ for 10 min. The PCR products were visualized using agarose gel electrophoresis and a gel imager. Sequencing was performed by Majorbio Bio-Pharm Technology Corp. Ltd. (Shanghai, China).

The $16 \mathrm{~S}$ rRNA gene sequences were analyzed using the SeqMan software (DNA Star, Madison, WI), and the identities of the bacterial isolates were determined using the BLAST algorithm (http://www.ncbi.nlm.nih .gov/blast; Altschul et al., 1997). Sequences generated in this work were submitted to the National Center for Biotechnology Information database (http://www.blast .ncbi.nlm.nih.gov) under accession numbers MH891655 to MH891726 and IMAU11991 to IMAU12061. The 16S rRNA gene sequences of the type strains were retrieved from the List of Prokaryotic Names with Standing in Nomenclature (LPSN; http://www.bacterio.net/), and a phylogenetic tree was created with sequences of the isolated LAB using the MEGA software (version 7.0; http://www.megasoftware.net; Tamura et al., 2007).

\section{DNA Extraction for SMRT Sequencing}

The bacterial microbiota of 10 fresh camel milk samples were determined. Total DNA was extracted from $1.5 \mathrm{~mL}$ of each sample using a modified cetyltrimethylammonium bromide (CTAB) method (Doyle et al., 2016) with the Soil DNA Extraction kit (Omega Bio-Tek, Norcross, GA). The quality of the extracted DNA was checked by agarose gel electrophoresis and spectrophotometry (Thermo Fisher Scientific).

\section{PCR and SMRT Sequencing for Microbiota Profiling}

The forward 27F (5'-GAGAGTTTGATCCTGGCTCAG-3') and reverse 1541R (5'-AAGGAGGTGATCCAGCCGCA-3') primers were used to amplify the fulllength 16S rRNA gene from genomic DNA extracted from the camel milk. The volume of reaction mixture was $25 \mu \mathrm{L}$. The reaction conditions were as follows: $95^{\circ} \mathrm{C}$ for $3 \mathrm{~min}, 30$ cycles of $98^{\circ} \mathrm{C}$ for $20 \mathrm{~s}, 58^{\circ} \mathrm{C}$ for $15 \mathrm{~s}$, and $72^{\circ} \mathrm{C}$ for $1.5 \mathrm{~min}$, with a final extension of $72^{\circ} \mathrm{C}$ for 1 min. The Agilent DNA 1000 Kit and an Agilent 2100 Bioanalyzer (Agilent Technologies, Santa Clara, CA) were used to check the quality of the PCR products. The purified amplification products were sequenced using the P6-C4 chemistry (Pacific Biosciences) on the PacBio RS II platform (Pacific Biosciences).

\section{Bioinformatics Processing}

Raw data were analyzed with RS-ReadsOfinsert.1 of SMRT Portal (version 2.7, Pacific Biosciences). The sequence filter parameter criteria, including the minimum full passes, minimum predicted accuracy, minimum read lengths, and maximum read lengths, were set to 5, 90, 1,400, and 1,800, respectively (Hou et al., 2015). The barcode and primer sequences were removed to create the data set. Then, PyNAST (Caporaso et al., 2010) was applied to align the extracted high-quality sequences, and UCLUST (Edgar, 2010) was used to classify operational taxonomic units (OTU) under a threshold of $97 \%$ (Lozupone et al., 2006). A de novo taxonomic tree was constructed as described in Price et al. (2010). Alpha diversity was evaluated with the Chao1 richness estimator, the Shannon-Wiener diversity index, and the Simpson diversity index.

\section{Statistical Analysis}

Graphic presentations were generated by the Origin software version 8.5 (OriginLab Corp., Hampton, MA). The co-occurrence and co-exclusion relationships were plotted with the Corrplot package under the $\mathrm{R}$ environment (http://www.r-project.org). Spearman correlation coefficients (r) were used to determine relationships between relative abundances of identified bacterial sequences.

\section{RESULTS}

\section{Physicochemical Properties}

The average contents of fat, total protein, nonfat milk solids, acidity, and density of the 10 milk samples were (mean $\pm \mathrm{SD}$ ) $4.40 \pm 0.82 \%$ (range: $2.79-5.51 \%$ ), 3.87 $\pm 0.29 \%(3.39-4.36 \%), 9.50 \pm 0.47 \%$ (8.58-10.3\%), $16.95 \pm 1.65^{\circ} \mathrm{T}\left(13.5-19.7^{\circ} \mathrm{T}\right)$, and $1.02 \pm 0.03 \mathrm{~g} / \mathrm{cm}^{3}$ $\left(0.98-1.06 \mathrm{~g} / \mathrm{cm}^{3}\right)$, respectively.

\section{$L A B$ Counts and Isolation}

The average LAB viable count was $6.02 \times 10^{3} \mathrm{cfu} /$ $\mathrm{mL}$, ranging from $6.35 \times 10^{2} \mathrm{cfu} / \mathrm{mL}$ to $5.55 \times 10^{4}$ 
$\mathrm{cfu} / \mathrm{mL}$. A total of $72 \mathrm{LAB}$ strains were isolated, 31 and 41 from MRS and M17 medium, respectively. They were all presumptive LAB based on gram-positive and catalase-negative characteristics. All were further identified to the species level by $16 \mathrm{~S}$ rRNA gene sequencing. A phylogenetic tree was constructed to show evolutionary relationships among them and representative type strains (Supplemental Figure S1; https://doi.org/10 .3168/jds.2019-17023). The 72 LAB strains belonged to 4 genera (Lactobacillus, Lactococcus, Weissella, and Enterococcus). They were identified as Lactobacillus paracasei (26 strains), Enterococcus italicus (23 strains), Enterococcus durans (12 strains), Enterococcus faecium (1 strain), Lactococcus lactis ssp. lactis (8 strains), and Weissella confusa (2 strains). Among them, Lactobacillus paracasei accounted for the highest proportion (36.1\%), followed by Enterococcus italicus (31.9\%). In addition to LAB strains, we found some potential pathogens in the fresh camel milk, including Raoultella ornithinolytica, Streptococcus gallolyticus, Streptococcus suis, Staphylococcus aureus, and Streptococcus uberis.

\section{Richness, Diversity, and Composition of Camel Milk Bacterial Microbiota}

Genomic DNA was extracted from 10 camel samples. A total of 58,806 high-quality sequences were obtained (average of 5,880.6 per sample), corresponding to 8,513 OTU (average of $851.3 \mathrm{OTU} /$ sample). The $\alpha$ diversity indices of samples are shown in Table 1. The Shannon, Chao 1, and Simpson indices and the number of observed species ranged from 3.87 to $8.01,527.49$ to $2,243.24,0.85$ to 0.98 , and 185.14 to 880.42 , respectively.

Bacterial diversity and richness were also evaluated by rarefaction curves (Figure 1a) and Shannon diversity index curves (Figure 1b). As shown in Figure 1a, the rarefaction curves of all samples were not saturated, suggesting that new bacterial species might still be detected if sequencing depth increased. The Shannon index curves (Figure 1b), however, reached a plateau, suggesting that the current sequencing depth was enough to cover the bacterial diversity. A large Shannon diversity index indicates high bacterial diversity. Based on the current data, samples XT10 and XT2 had the highest and lowest bacterial diversity, respectively.

\section{Camel Milk Bacterial Microbiota}

The 8,513 identified OTU were assigned to 32 phyla, 76 classes, 109 orders, 173 families, 377 genera, and 652 species (data not shown). All samples showed a similar microbiota structure at the phylum level. The dominant bacterial phyla (with mean relative abundance $>1 \%$ ) are shown in Table 2 and were Proteobacteria (50.34\%), Firmicutes (27.95\%), Deinococcus-Thermus (14.25\%), Bacteroidetes (4.08\%), and Actinobacteria (1.95\%).

At the genus level (Table 2; Figure 2a), 10 dominant bacterial genera (average relative abundance $>1 \%$ ) could be identified, including Pseudomonas (29.92\%), Thermus (14.10\%), Streptococcus (10.04\%), Acinetobacter $(7.45 \%)$, Lactobacillus (3.67\%), Moraxella (1.96\%), Lactococcus (1.71\%), Naxibacter (1.49\%), Leuconostoc (1.43\%), Paenibacillus $(1.21 \%)$, Propionibacterium $(1.05 \%)$, and Neisseria (1.04\%). It is interesting to note that Proteobacteria and Pseudomonas were the predominant phylum and genus in sample XT2, comprising $94.44 \%$ and $93.70 \%$ (Figure $2 \mathrm{a}$ ) of total sequences, respectively; these results were consistent with the observed low bacterial diversity of this sample.

At the species level, 12 dominant bacterial species ( $>1 \%$ of average relative abundance each) were identified: Thermus scotoductus (14.10\%), Streptococcus thermophilus (8.57\%), Pseudomonas veronii (7.44\%), Pseudomonas fragi (5.37\%), Pseudomonas cedrina (5.20\%), Acinetobacter lwoffii (4.27\%), Acinetobacter johnsonii (2.82\%), Lactobacillus helveticus (2.33\%), Lactococcus lactis (1.69\%), Naxibacter alkalitolerans (1.45\%), Leu-

Table 1. Sequence abundance and microbial diversity of samples

\begin{tabular}{|c|c|c|c|c|c|c|}
\hline Sample & No. of reads & No. of OTU ${ }^{1}$ & $\begin{array}{l}\text { Shannon } \\
\text { index }\end{array}$ & $\begin{array}{l}\text { Simpson } \\
\text { index }\end{array}$ & $\begin{array}{l}\text { Chao1 } \\
\text { index }\end{array}$ & $\begin{array}{c}\text { No. of } \\
\text { observed species }\end{array}$ \\
\hline $\mathrm{XT} 2$ & 6,381 & 291 & 3.87 & 0.85 & 527.49 & 185.14 \\
\hline XT3 & 4,853 & 496 & 5.00 & 0.90 & $1,007.46$ & 367.40 \\
\hline $\mathrm{XT} 4$ & 7,897 & 1,375 & 7.30 & 0.96 & $1,713.93$ & 809.14 \\
\hline XT5 & 6,104 & 890 & 5.78 & 0.94 & $1,442.00$ & 574.74 \\
\hline XT7 & 6,955 & 864 & 5.62 & 0.90 & $1,300.95$ & 514.16 \\
\hline XT8 & 3,209 & 771 & 6.61 & 0.93 & $2,243.24$ & 753.38 \\
\hline XT10 & 4,406 & 1,093 & 8.01 & 0.98 & $2,069.67$ & 880.42 \\
\hline $\mathrm{XT} 12$ & 6,972 & 974 & 6.48 & 0.95 & $1,183.60$ & 643.38 \\
\hline XT13 & 4,255 & 622 & 5.81 & 0.93 & $1,480.20$ & 367.40 \\
\hline XT15 & 7,774 & 1,137 & 6.64 & 0.94 & $1,511.31$ & 661.94 \\
\hline Mean \pm SD & $5,880.60 \pm 1,609.25$ & $851.30 \pm 321.49$ & $6.11 \pm 1.17$ & $0.92 \pm 0.03$ & $1,447.98 \pm 497.50$ & $575.71 \pm 219.60$ \\
\hline
\end{tabular}

${ }^{1} \mathrm{OTU}=$ operational taxonomic units. 
conostoc mesenteroides (1.43\%), and Propionibacterium acnes $(1.03 \%)$ (Table 2). Relatively large variation was found in the species-level composition between samples. For example, Pseudomonas veronii dominated samples XT2, XT5, XT12, contributing 26.69, 13.30, and $13.08 \%$ (Table 2) of the total sequence, respectively. The second dominant species, Pseudomonas fragi, represented 11.76 and $12.03 \%$ in samples XT5 and XT12, whereas Pseudomonas cedrina represented $18.98 \%$ of the total sequence in sample XT2 (Table 2). Thermus scotoductus was the predominant species in samples XT4, XT7, XT8, and XT15, representing
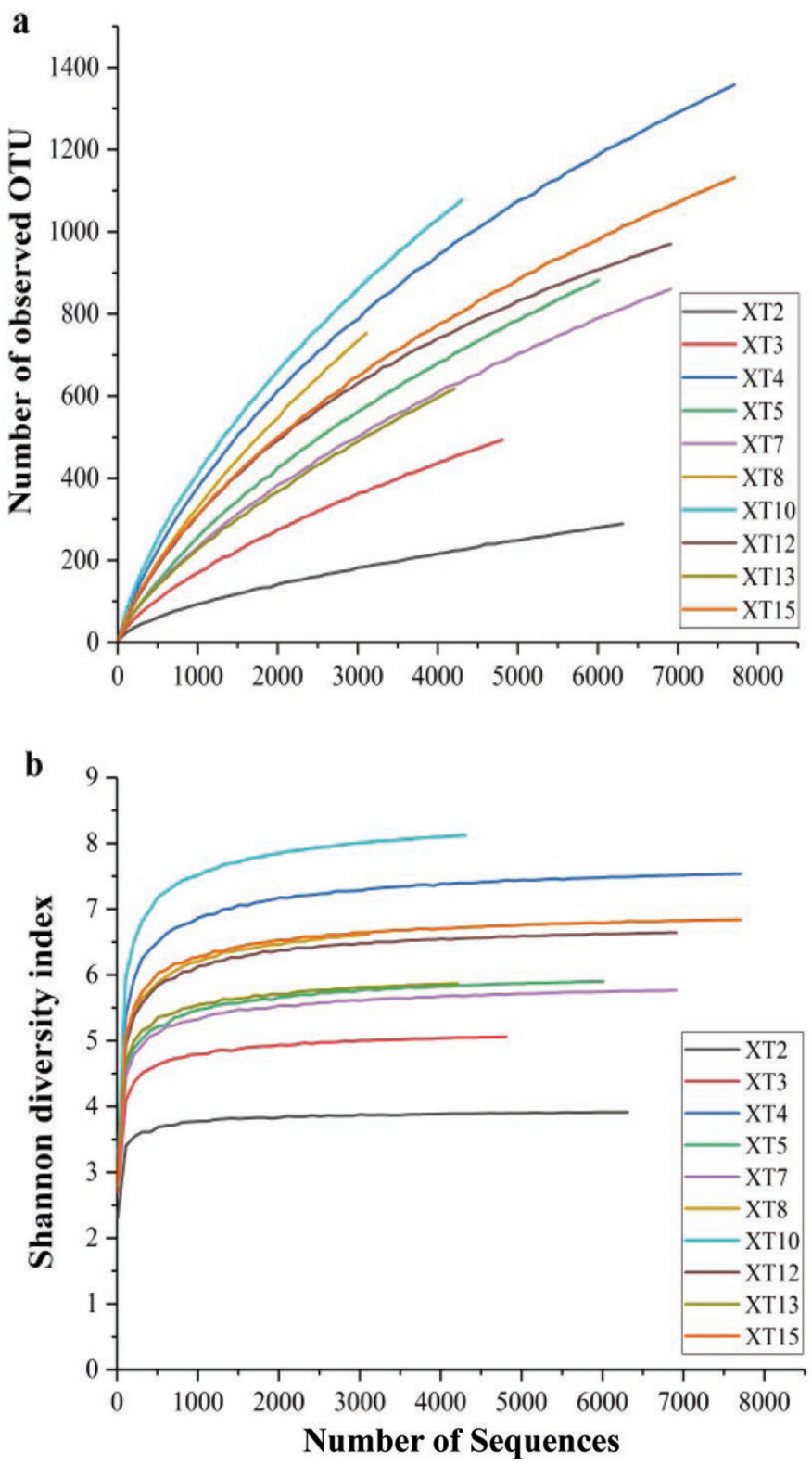

Figure 1. Rarefaction curves (a) and Shannon diversity index (b) of all samples (XT). OTU = operational taxonomic units.
$21.62,38.12,32.03$, and $29.06 \%$ (Table 2 ) of the total sequence, respectively. Some samples had unique representative species. For example, the relative abundances of Acinetobacter lwoffii (23.41\%) and Lactococcus lactis (14.84\%) were highest in samples XT13 and XT10, respectively. Sample XT3 was enriched in Streptococcus thermophilus (46.57\%) and Lactobacillus helveticus (15.91\%) (Table 2).

\section{Correlations Among Detected Camel Milk Taxa}

Because the intrinsic microbes present in the milk interactively modulate the milk microbiota structure, correlation analysis was performed among detected camel milk taxa of relative abundance $>0.3 \%$ (Figure $3)$. Interesting and significant co-occurrence relationships were detected among some LAB. For example, Lactobacillus helveticus showed strong correlations with Streptococcus thermophilus and Lactobacillus fermentum $(P<0.001 ; \mathrm{r}=0.9084$ and 0.9211 , respectively $)$. Moreover, the most dominant species of the camel milk microbiota, Thermus scotoductus, was positively and strongly correlated with Brevundimonas terrae $(P$ $<0.01, \mathrm{r}=0.7988)$. A few taxa showed negative correlations. For instance, Massilia timonae co-excluded the presence of Pseudomonas veronii $(P<0.05, \mathrm{r}=$ $-0.6849)$ and the presence of Pseudomonas cedrina $(P$ $<0.05, \mathrm{r}=-0.6712$; Figure 3 ).

\section{DISCUSSION}

Camels produce milk that provides valuable nutrients for nomadic families living in harsh environments (Alwan et al., 2014). In this study, we first assessed the physicochemical properties of camel milk. A previous work characterized the composition and physicochemical properties of Chinese Bactrian camel milk (Zhao et al., 2015), including the contents of total protein and fat, as well as milk acidity and density. Generally, the values for the current batch of camel milk were lower than those reported in Zhao et al. (2015). Many factors can affect the physicochemical parameters. For example, milk density and fat usually peak during the first stage of lactation (Hadef et al., 2018). The lower acidity of the current batch of camel milk could be related to bacterial richness in the milk; specifically, LAB could decompose lactose to produce lactic acid and increase the milk acidity. The lower acidity could also result from the quantity and type of feeds available in the local area (Alwan et al., 2014). Protein content (casein and whey proteins) might vary due to camel breed and season of milk collection (Sawaya et al., 1984; Elamin and Wilcox, 1992; Al Haj and Al Kanhal, 2010). Nonfat milk solids refers to all substances except fat and water 


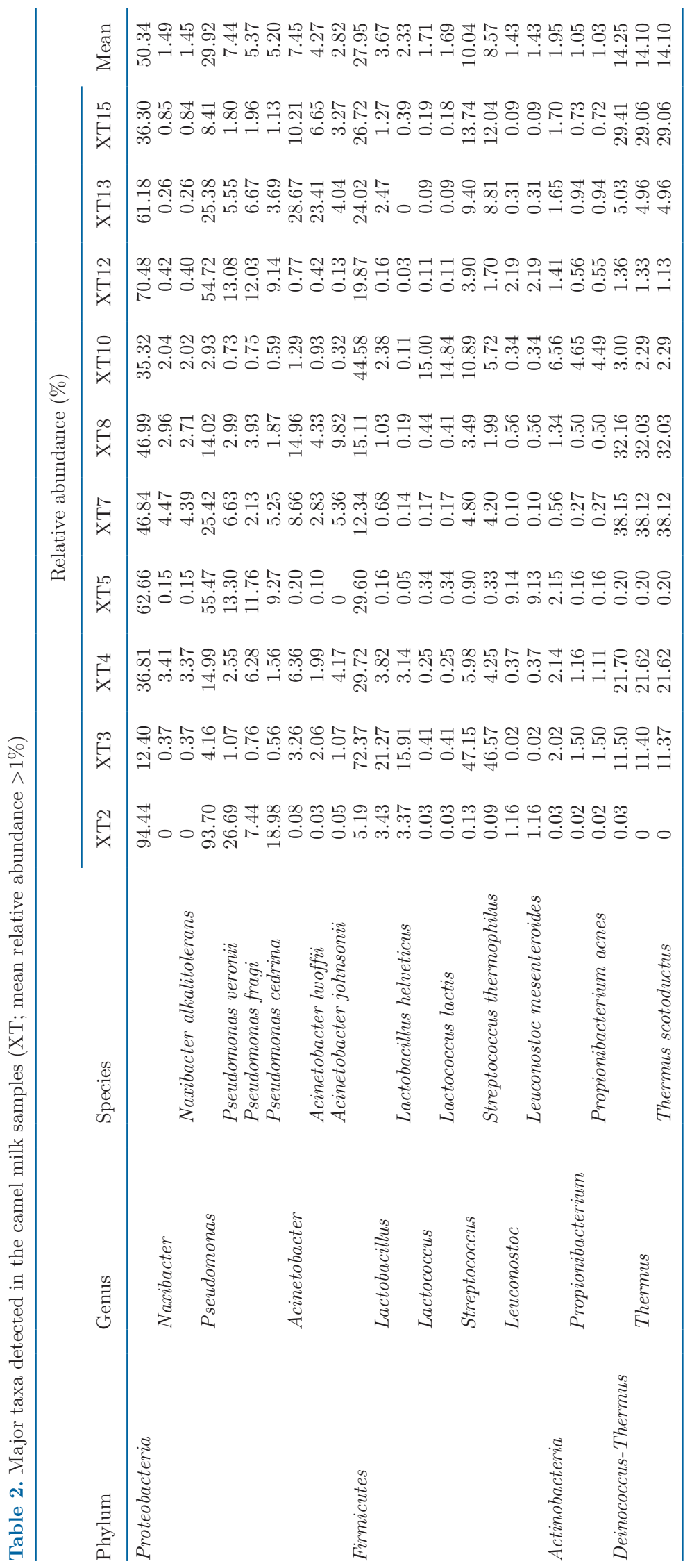


a

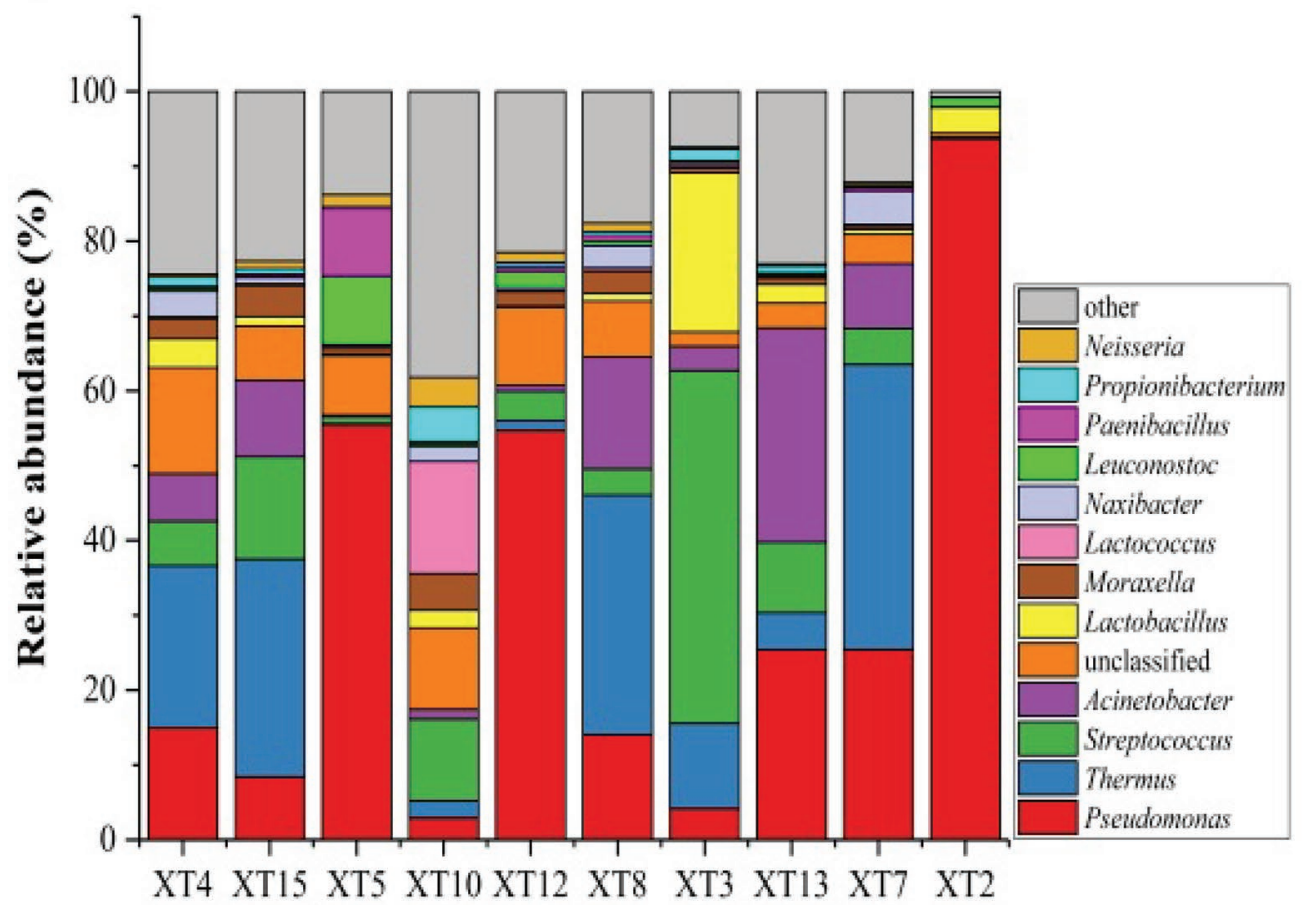

Genus level

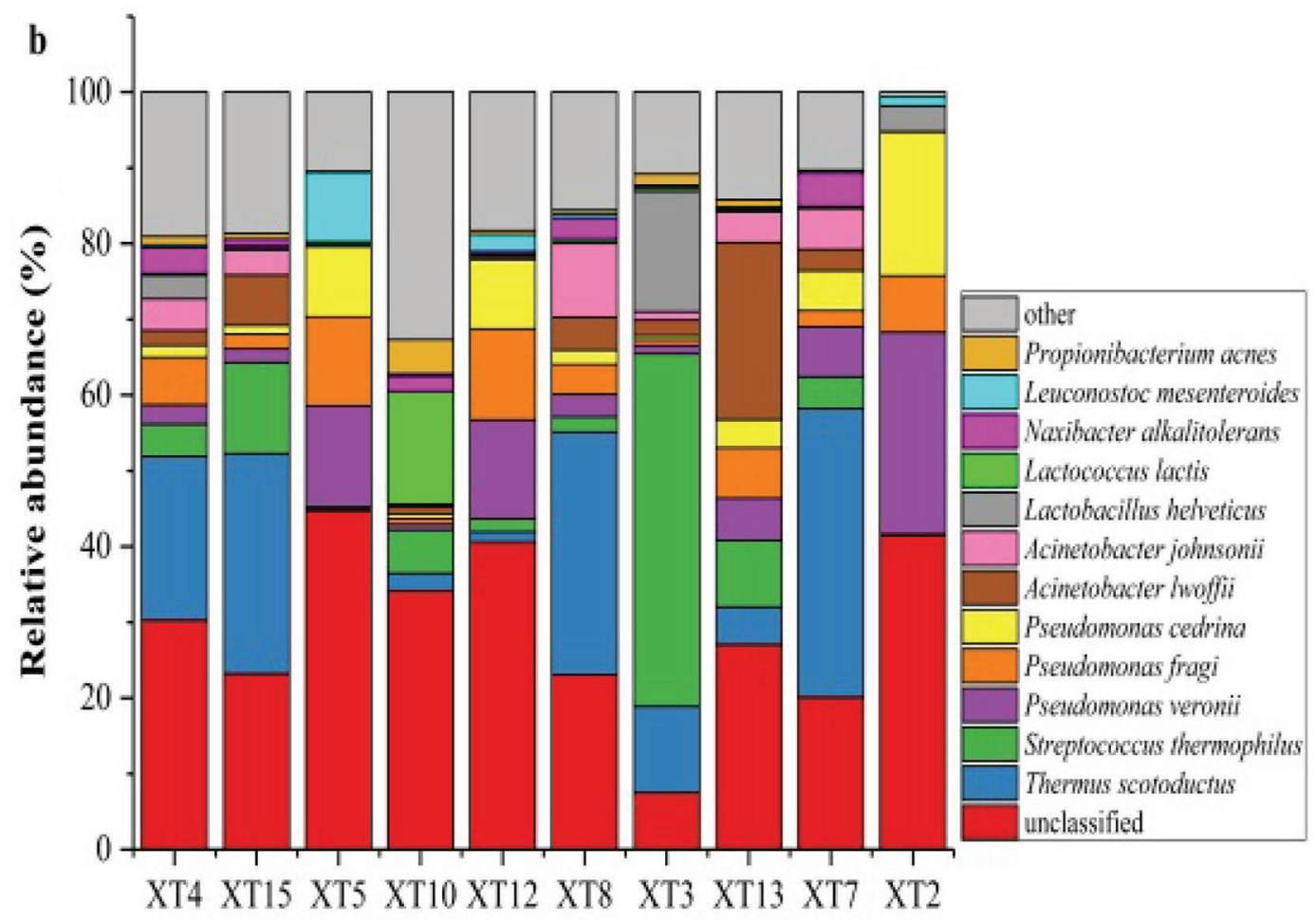

Species level

Figure 2. Relative abundances and bacterial diversity at the genus (a) and species (b) levels. XT $=$ sample. 


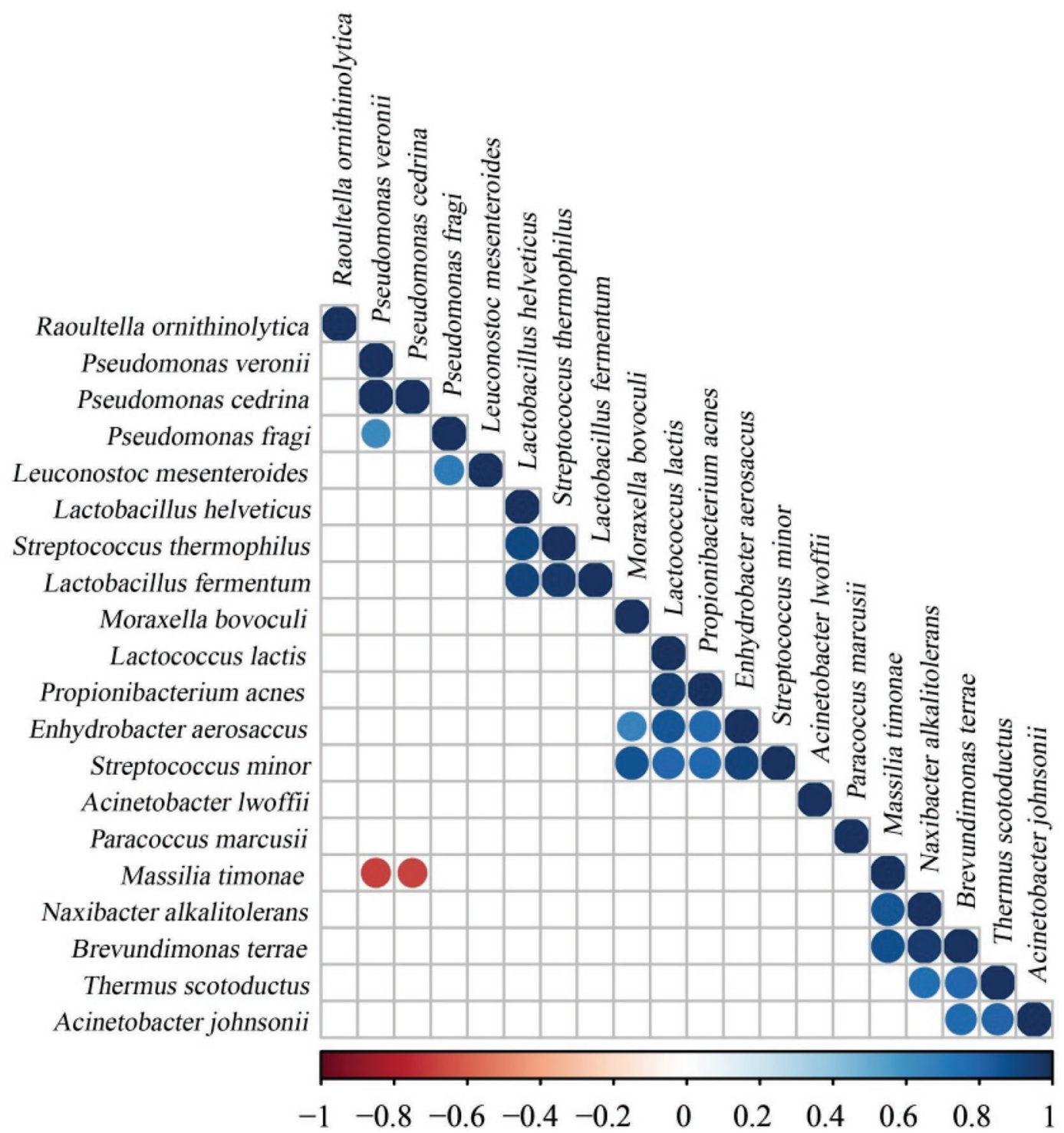

Figure 3. Correlations among major bacterial species. Spearman rank correlation matrix of species with relative abundance $>0.3 \%$ was included in the analysis. The color of the scale bar represents the nature and strength of correlation, with 1 indicating a perfectly positive correlation (dark blue) and -1 indicating a perfectly negative correlation (dark red) between 2 items. Only correlations with $P$-value $<0.05$ are shown.

in milk, and it is often used as an indicator for measuring the quality of fresh milk (Ji et al., 2011). Compared with that reported in Zhang et al. (2016), a comparable level of nonfat milk solids was present in the current samples. In addition to the influencing factors stated above, factors such as geographic area, feeding conditions, physiological variations, and genetic or health status play important roles in shaping the composition of camel milks (Konuspayeva et al., 2009).

Fresh camel milk is a potential source of novel LAB of high probiotic potential (Abushelaibi et al., 2017; Ayyash et al., 2018). Our study isolated 72 LAB strains from fresh camel milk; the LAB plate count was 6.02 $\times 10^{3} \mathrm{cfu} / \mathrm{mL}$. Enterococcus and Lactobacillus were the dominant genera and the predominant species were Enterococcus italicus and Lactobacillus paracasei. Benkerroum et al. (2003), however, reported a much higher LAB count $\left(1 \times 10^{7} \mathrm{cfu} / \mathrm{mL}\right)$ in raw camel milk collected in Morocco. The bacteria in the study by Benkerroum et al. (2003) mainly belonged to the genus Enterococcus, particularly the species Enterococcus faecalis. A similar level of LAB count was reported in camel milk collected in south Morocco (Khedid et al., 2009). The dominant taxa were Lactobacillus, and Lactococcus lactis ssp. lactis. Yamina et al. (2013) found 30 strains of LAB from camel milk collected in Algerian, 
and Ayyash et al. (2018) found 23 strains of LAB in camel milk collected from farms in Abu Dhabi, Saudi Arabia, and the United Arab Emirates. To sum up, the quantity and types of LAB can vary greatly among milk samples collected in different geographical regions.

Using SMRT technology, we profiled the bacterial microbiota of the camel milk samples. A high relative abundance of sequences representing the species Streptococcus thermophilus, Lactobacillus helveticus, Lactococcus lactis, and Leuconostoc mesenteroides. The rich LAB composition might function as natural antibacterial agents that enhance the shelf life of camel milk and its products, as well as serving as beneficial microorganisms (Benkerroum et al., 2003). The health-promoting effects of LAB have received much attention. Milk fermented by Leuconostoc mesenteroides shows high antioxidant activity; that is, 1,1-diphenyl-2-picrylhydrazyl (and 2, 2'-azinobis (3-ethylbenzothiazoline-6-sulfonic acid) radical scavenging activities, as well as high overall acceptance values compared with samples fermented by other strains (Soleymanzadeh et al., 2016). Lactic acid bacteria isolated from camel milk can also be used to produce other fermented dairy products because of their high acidifying and proteolytic activities (Fguiri et al., 2016).

Milk is generally produced in a traditional manufacture line, including the processes of milk collection, storage, handling, and transportation under strict sanitary conditions (David, 2012; Gautret et al., 2013). Some $16 \mathrm{~S}$ rRNA sequences detected by SMRT technology represent potential contaminants and pathogens. The prevalence of certain microbes could undoubtedly reflect the hygienic conditions of milk production. For example, the Pseudomonas genus has been consistently reported to be dominant microbes of raw milk (Sørhaug and Stepaniak, 1997; Quigley et al., 2013; Soto Del Rio et al., 2017). Our current data showed a high relative abundance of Pseudomonas $(>34 \%)$ in samples XT2, $\mathrm{XT} 5$, and XT12. The low storage temperature of milk (usually 1 to $4^{\circ} \mathrm{C}$ ) makes it favorable for the survival of some common spoilage microbes such as Pseudomonas (De Jonghe et al., 2011). Our study also observed sequences representing the psychrotolerant species Pseudomonas fragi. In contrast, sequences of some extreme thermophilic bacteria, namely Thermus, were observed. These bacteria are not generally associated with milk. The current results, however, showed for the first time the connection between Thermus scotoductus and camel milk. This species can be isolated from hot tap water and other thermal sources, and they preferentially live at a temperature of 70 to $75^{\circ} \mathrm{C}$ (Brock and Freeze, 1969). Water can be a significant source of microbial contamination in milk because many local farms simply wash milking equipment using waters from wells, lakes, and rivers. Thus, local waters and their associated microflora could become major milk contaminant sources. Dairy safety assessment based on Propionibacterium was described by Meile et al. (2008). Our work found sequences that corresponded to the species Propionibacterium acnes, which is generally associated with human skin. Most of the camels in the Alxa area are maintained by artificial rearing; thus, they might have frequent human contact, potentially leading to the transfer of this bacterium to camel milk. Some sequences represented members of other genera (namely Acinetobacter, Moraxella, Naxibacter, Paenibacillus, and Neisseria) that are considered environmental microorganisms from various sources, including soil, sludge, water, and dust (Spain et al., 1979; Berge et al., 2002; Carr et al., 2003; $\mathrm{Xu}$ et al., 2005). They could be acquired from the living environment of the camel, residing on the animal body and eventually contaminating camel milk during milk collection and production.

Strong positive correlations existed among the LAB species Lactobacillus helveticus, Streptococcus thermophilus, and Lactobacillus fermentum. These bacteria are commonly found in cheese whey starters, and together they contribute to the high viable counts of some related products (Rossetti et al., 2008). The distribution of these bacteria is mainly dairy plant-specific rather than correlated with geographical fluctuations (Rossetti et al., 2008).

Our study investigated the camel milk bacterial community using both culture-dependent methods and PacBio SMRT technology. Previous work showed that the results obtained from these 2 approaches are largely consistent (Mo et al., 2019). The data of Mo et al. (2019) from laboratory cultivation and PacBio SMRT technology consistently found that Lactobacillus helveticus was the most abundant species, although it has been hard to correlate the data set generated by the 2 approaches because of the principle of the methods (for culture-dependent methods, the separation of lactic acid bacteria is mainly dependent on the selected medium, and for PacBio SMRT technology, the method is mainly captured DNA sequences). However, we found no correlation between culture-dependent and culture-independent results. For example, in our study, Lactobacillus paracasei represented a high proportion of viable microorganisms but a low relative abundance of sequences detected by SMRT sequencing (0.08\%; data not shown). Moreover, although a relatively high proportion of sequences represented Streptococcus thermophilus, this species was not recovered in culture. The discrepancies of results generated by culture-dependent and culture-independent approaches are likely explained 
by technicalities such as specific growth requirements for certain bacteria and possible PCR amplification bias.

\section{CONCLUSIONS}

We analyzed the bacterial microbiota profile of 10 camel milk samples by PacBio SMRT sequencing technology; the bacterial microbiota profile was highly diverse among samples. We also isolated and identified 72 LAB strains (distributed in 6 different species) by culture-dependent techniques from 15 samples. Among the 6 species, Lactobacillus paracasei $(36.1 \%)$ and Enterococcus italicus (31.9\%) were most often encountered. This work provides interesting physicochemical and taxonomic data of camel milk, which has not been studied systematically before.

\section{ACKNOWLEDGMENTS}

This research was supported by the Earmarked fund for the National Key R\&D Program of the 13th FiveYear Plan of China (grant no. 2018YFD0400102), the National Natural Science Foundation of China (grant no. 31571814), and the China Agriculture Research System (grant no. CARS-36).

\section{REFERENCES}

Abushelaibi, A., S. Al-Mahadin, K. El-Tarabily, N. P. Shah, and M. Ayyash. 2017. Characterization of potential probiotic lactic acid bacteria isolated from camel milk. Lebensm. Wiss. Technol. 79:316-325.

Al Haj, O. A., and H. A. Al Kanhal. 2010. Compositional, technological and nutritional aspects of dromedary camel milk. Int. Dairy J. 20:811-821.

Altschul, S. F., T. L. Madden, A. A. Schäffer, J. Zhang, Z. Zhang, W. Miller, and D. J. Lipman. 1997. Gapped BLAST and PSI-BLAST: A new generation of protein database search programs. Nucleic Acids Res. 25:3389-3402.

Alwan, O. A., A. O. Igwegbe, and A. A. Ahmad. 2014. Effects of rearing conditions on the proximate composition of Libyan Maghrebi camels' (Camelus dromedarius) milk. Int. J. Eng. 4:8269.

Ayyash, M., A. Abushelaibi, S. Al-Mahadin, M. Enan, K. El-Tarabily, and N. Shah. 2018. In vitro investigation into probiotic characterisation of Streptococcus and Enterococcus isolated from camel milk. Lebensm. Wiss. Technol. 87:478-487.

Bai, Y., D. Zhao, and H. Zhang. 2009. Physiochemical properties and amino-acid composition of Alxa Bactrian camel milk and shubat. J. Camel Pract. Res. 16:245-251.

Benkerroum, N., A. Boughdadi, N. Bennani, and K. Hidane. 2003. Microbiological quality assessment of Moroccan camel's milk and identification of predominating lactic acid bacteria. World J. Microbiol. Biotechnol. 19:645-648.

Berge, O., M. H. Guinebretière, W. Achouak, P. Normand, and T. Heulin. 2002. Paenibacillus graminis sp. nov. and Paenibacillus odorifer sp. nov., isolated from plant roots, soil and food. Int. J. Syst. Evol. Microbiol. 52:607-616.

Brock, T. D., and H. Freeze. 1969. Thermus aquaticus gen. nov. and sp. nov., a nonsporulating extreme thermophile. J. Bacteriol. 98:289-297.
Bulca, S. 2017. Functional properties of camel milk and their influences on technological applications. Sci. Bull. Ser. F Biotechnol. $21: 275-283$

Caporaso, J. G., K. Bittinger, F. D. Bushman, T. Z. Desantis, G. L. Andersen, and R. Knight. 2010. PyNAST: A flexible tool for aligning sequences to a template alignment. Bioinformatics 26:266-267. https://doi.org/10.1093/bioinformatics/btp636.

Carr, E. L., P. Kämpfer, B. K. Patel, V. Gürtler, and R. J. Seviour. 2003. Seven novel species of Acinetobacter isolated from activated sludge. Int. J. Syst. Evol. Microbiol. 53:953-963.

China Statistical Yearbook. 2013. China Statistics Press, Beijing, China.

David, S. D. 2012. Raw milk in court: Implications for public health policy and practice. Public Health Rep. 127:598-601.

De Jonghe, V., A. Coorevits, K. Van Hoorde, W. Messens, A. Van Landschoot, P. De Vos, and M. Heyndrickx. 2011. Influence of storage conditions on the growth of Pseudomonas species in refrigerated raw milk. Appl. Environ. Microbiol. 77:460-470.

Dong, F., D. A. Hennessy, and H. H. Jensen. 2012. Factors determining milk quality and implications for production structure under somatic cell count standard modification. J. Dairy Sci. 95:6421-6435.

Doyle, C. J., D. Gleeson, P. W. O'Toole, and P. D. Cotter. 2016 Impacts of seasonal housing and teat preparation on raw milk microbiota: A high-throughput sequencing study. Appl. Environ. Microbiol. 83:e2694-16.

Edgar, R. C. 2010. Search and clustering orders of magnitude faster than BLAST. Bioinformatics 26:2460-2461. https://doi.org/10 .1093/bioinformatics/btq461.

El-Agamy, E. I., M. Nawar, S. M. Shamsia, S. Awad, and G. F Haenlein. 2009. Are camel milk proteins convenient to the nutrition of cow milk allergic children? Small Rumin. Res. 82:1-6.

Elamin, F. M., and C. J. Wilcox. 1992. Milk composition of Majaheim camels. J. Dairy Sci. 75:3155-3157.

Ercolini, D. 2013. High-throughput sequencing and metagenomics: Moving forward in the culture-independent analysis of food microbial ecology. Appl. Environ. Microbiol. 79:3148-3155.

Fguiri, I., M. Ziadi, M. Atigui, N. Ayeb, S. Arroum, M. Assadi, and T. Khorchani. 2016. Isolation and characterisation of lactic acid bacteria strains from raw camel milk for potential use in the production of fermented Tunisian dairy products. Int. J. Dairy Technol. 69:103-113.

Gautret, P., S. Benkouiten, C. Gaillard, P. Parola, and P. Brouqui. 2013. Camel milk-associated infection risk perception and knowledge in French Hajj pilgrims. Vector Borne Zoonotic Dis. 13:425427.

Hadef, L., H. Aggad, B. Hamad, and M. Saied. 2018. Study of yield and composition of camel milk in Algeria. Food Ind. 19:1-11.

Heikkilä, M. P., and P. E. J. Saris. 2003. Inhibition of Staphylococcus aureus by the commensal bacteria of human milk. J. Appl. Microbiol. 95:471-478.

Hou, Q., H. Xu, Y. Zheng, X. Xi, L. Y. Kwok, Z. Sun, H. Zhang, and W. Zhang. 2015. Evaluation of bacterial contamination in raw milk, ultra-high temperature milk and infant formula using single molecule, real-time sequencing technology. J. Dairy Sci. 98:84648472 .

Jans, C., J. Bugnard, P. M. K. Njage, C. Lacroix, and L. Meile. 2012. Lactic acid bacteria diversity of African raw and fermented camel milk products reveals a highly competitive, potentially healththreatening predominant microflora. Lebensm. Wiss. Technol. 47:371-379.

Ji, S., Q. Zhou, and J. Feng. 2011. Analysis of major nutritional components in fresh milk from different areas of Liaoning. Food Sci. $32: 316-318$

Jin, H., L. Mo, L. Pan, Q. Hou, and J. Yu. 2018. Using PacBio sequencing to investigate the bacterial microbiota of traditional Buryatian cottage cheese and comparison with Italian and Kazakhstan artisanal cheeses. J. Dairy Sci. 101:6885-6896.

Kadim, I. T., O. Mahgoub, and R. W. Purchas. 2008. A review of the growth, and of the carcass and meat quality characteristics of the one-humped camel (Camelus dromedaries). Meat Sci. 80:555-569. 
Khedid, K., M. Faid, A. Mokhtari, A. Soulaymani, and A. Zinedine. 2009. Characterization of lactic acid bacteria isolated from the one humped camel milk produced in Morocco. Microbiol. Res. 164:81-91.

Konuspayeva, G., B. Faye, and G. Loiseau. 2009. The composition of camel milk: A meta-analysis of the literature data. J. Food Compos. Anal. 22:95-101.

Kula, J. T., and D. Tegegne. 2016. Chemical composition and medicinal values of camel milk. Int. J. Res. Stud. Biosci. 4:13-25.

Leroy, F., and L. De Vuyst. 2004. Lactic acid bacteria as functional starter cultures for the food fermentation industry. Trends Food Sci. Technol. 15:67-78

Li, J., Y. Zheng, H. Xu, X. Xi, Q. Hou, S. Feng, L. Wuri, Y. Bian, Z. Yu, L. Y. Kwok, Z. Sun, and T. Sun. 2017. Bacterial microbiota of Kazakhstan cheese revealed by single molecule real time (SMRT) sequencing and its comparison with Belgian, Kalmykian and Italian artisanal cheeses. BMC Microbiol. 17:13.

Lozupone, C., M. Hamady, and R. Knight. 2006. UniFrac-An online tool for comparing microbial community diversity in a phylogenetic context. BMC Bioinformatics 7:371.

Meile, L., G. Le Blay, and A. Thierry. 2008. Safety assessment of dairy microorganisms: Propionibacterium and Bifidobacterium. Int. J. Food Microbiol. 126:316-320.

Mo, L., J. Yu, H. Jin, Q. Hou, C. Yao, D. Ren, X. An, T. Tsogtgerel, and H. Zhang. 2019. Investigating the bacterial microbiota of traditional fermented dairy products using propidium monoazide with single-molecule real-time sequencing. J. Dairy Sci. 102:3912-3923.

Mosher, J. J., B. Bowman, E. L. Bernberg, O. Shevchenko, J. Kan, J. Korlach, and L. A. Kaplan. 2014. Improved performance of the PacBio SMRT technology for 16S rDNA sequencing. J. Microbiol. Methods 104:59-60.

National Food Safety Standard. 2010. Determination of nonfat total milk solids in milk and milk products. GB5413.39-2010. Ministry of Health of the People's Republic of China, Beijing, China.

National Food Safety Standard. 2016a. Determination of acidity in food. GB5009.239-2016. National Health and Family Planning Commission of the PRC, Beijing, China.

National Food Safety Standard. 2016b. Determination of relative density of foods. GB5009.2-2016. National Health and Family Planning Commission of the PRC, Beijing, China.

National Food Safety Standard. 2016c. Determination of fat in foods. GB5009.6-2016. National Health and Family Planning Commission of the PRC, Beijing, China.

National Food Safety Standard. 2016d. Determination of protein in foods. GB5009.5-2016. National Health and Family Planning Commission of the PRC, Beijing, China

Omer, R. H., and A. H. Eltinay. 2008. Microbial quality of camel's raw milk in central \& southern regions of United Arab Emirates. Emir. J. Food Agric. 20:76-83.

Price, M. N., P. S. Dehal, and A. P. Arkin. 2010. FastTree 2-Approximately maximum-likelihood trees for large alignments. PLoS One 5:e9490.

Quigley, L., O. O'sullivan, C. Stanton, T. P. Beresford, R. P. Ross, G. F. Fitzgerald, and P. D. Cotter. 2013. The complex microbiota of raw milk. FEMS Microbiol. Rev. 37:664-698.

Rossetti, L., M. E. Fornasari, M. Gatti, C. Lazzi, E. Neviani, and G. Giraffa. 2008. Grana Padano cheese whey starters: Microbial composition and strain distribution. Int. J. Food Microbiol. 127:168171.
Sawaya, W., J. Khalil, A. Al-Shalhat, and H. Al-Mohammad. 1984. Chemical composition and nutritional quality of camel milk. J. Food Sci. 49:744-747.

Scarpellini, M., D. Mora, S. Colombo, and L. Franzetti. 2002. Development of genus/species-specific PCR analysis for identification of Carnobacterium strains. Curr. Microbiol. 45:24-29.

Shabo, Y., R. Barzel, M. Margoulis, and R. Yagel. 2005. Camel milk for food allergies in children. Isr. Med. Assoc. J. 7:796-798.

Shamsia, S. M. 2007. Nutritional and therapeutic properties of camel and human milks. Int. J. Genet. Mol. Biol. 1:52-58.

Soleymanzadeh, N., S. Mirdamadi, and M. Kianirad. 2016. Antioxidant activity of camel and bovine milk fermented by lactic acid bacteria isolated from traditional fermented camel milk (Chal). Dairy Sci. Technol. 96:443-457.

Sørhaug, T., and L. Stepaniak. 1997. Psychrotrophs and their enzymes in milk and dairy products: quality aspects. Trends Food Sci. Technol. 8:35-41.

Soto Del Rio, M. L., A. Dalmasso, T. Civera, and M. Bottero. 2017. Characterization of bacterial communities of donkey milk by highthroughput sequencing. Int. J. Food Microbiol. 251:67-72.

Spain, J. C., O. Wyss, and D. T. Gibson. 1979. Enzymatic oxidation of p-nitrophenol. Biochem. Biophys. Res. Commun. 88:634-641.

Tamura, K., J. Dudley, M. Nei, and S. Kumar. 2007. MEGA4: Molecular evolutionary genetics analysis (MEGA) software version 4.0 Mol. Biol. Evol. 24:1596-1599.

Teply, L. J. 1965. Role of milk and milk products in nutrition in tropical and subtropical countries. J. Dairy Sci. 48:1547-1550.

Wang, J., Y. Zheng, X. Xi, Q. Hou, H. Xu, J. Zhao, J. Li, Y. Bian, H. Ma, Y. Wang, L. Y. Kwok, H. Zhang, and Z. Sun. 2018. Application of PacBio. Single Molecule Real-Time (SMRT) sequencing in bacterial source tracking analysis during milk powder production. Food Control 93:226-234.

Xu, P., W. Li, S. Tang, Y. Zhang, G. Chen, H. Chen, L. Xu, and C. Jiang. 2005. Naxibacter alkalitolerans gen. nov., sp. nov., a novel member of the family 'Oxalobacteraceae' isolated from China. Int. J. Syst. Evol. Microbiol. 55:1149-1153.

Yagil, R. 1982. Camels and camel milk. FAO Anim. Prod. Health Paper 26. https://lib.ugent.be/catalog/rug01:001986152.

Yamina, M., C. Wassila, Z. Kenza, Z. Amina, S. Noureddine, H. J. Eddine, and K. Mebrouk. 2013. Physico-chemical and microbiological analysis of Algerian raw camel's milk and identification of predominating thermophilic lactic acid bacteria. J. Food Sci. Eng. 3:55.

Zhang, M., G. Chen, C. Zang, J. Dong, X. Huang, and D. Lu. 2016. Analysis of Physicochemical Indexes of Junggar Bactrian Camel Milk. China Animal Husbandry \& Veterinary Medicine.

Zhao, D., Y. Bai, and Y. Niu. 2015. Composition and characteristics of Chinese Bactrian camel milk. Small Rumin. Res. 127:58-67.

Zibaee, S., A. R. Hosseini, M. Yousefi, A. Taghipour, M. A. Kiani, and M. R. Noras. 2015. Nutritional and therapeutic characteristics of camel milk in children: A systematic review. Electron. Physician $7: 1523-1528$.

\section{ORCIDS}

Jingna Zhao 누 https://orcid.org/0000-0002-4907-1470

Lai-Yu Kwok @ https://orcid.org/0000-0001-8791-1269

Yongfu Chen ๑ https://orcid.org/0000-0003-2214-5836 